\title{
CONTRIBUIÇÕES DA ANÁLISE DO DISCURSO E DA EPISTEMOLOGIA DE FLECK PARA A COMPREENSÃO DA DIVULGAÇÃO CIENTÍFICA E SUA INTRODUÇÃO EM AULAS DE CIÊNCIAS
}

\author{
Tatiana Galieta Nascimento
}

Doutoranda do Programa de Pós-Graduação em Educação Científica e Tecnológica - UFSC

\section{Resumo}

Neste artigo a divulgação científica é entendida como produção de um círculo esotérico constituído por cientistas e jornalistas. Nele busco caracterizar as condições de produção deste tipo de texto tendo para tanto apoio em categorias da Análise do Discurso e da epistemologia de Fleck. A divulgação científica é compreendida em termos de circulação intercoletiva de idéias, ou seja, pelo fluxo de informações que ocorre entre o círculo esotérico e o círculo exotérico de não especialistas. Discuto ainda as implicações das mediações realizadas durante a produção dos textos de divulgação e sua inserção na sala de aula. Finalmente, comento a possibilidade de que estas mediações venham a se constituir obstáculos na aprendizagem formal de conceitos científicos sendo ressaltadas as relações entre os contextos de produção e significação dos textos de divulgação científica no processo de leitura.

Palavras-chave: divulgação científica; análise do discurso; Fleck; ensino de ciências.

\section{Contributions of Discourse Analysis and Fleck's epistemology to the comprehension of Popular Science and its introduction in science classrooms}

\section{Abstract}

In this article, the popular science is seen as production of an "esoteric" circle constituted by scientists and journalists and comprehended in terms of intercollective communication of ideas, i. e., by the exchange of information that occurs between the "esoteric" circle and the "exoteric" circle of non specialists. I try to characterize the conditions of production of the popular scientific text using categories of Discourse Analysis and Fleck's epistemology. I also argue the implications of the mediations that occur when the popular scientific text is produced and introduced in science classroom later. Finally, I discuss the possibility that those mediations might constitute obstacles for the formal scientific concepts learning. In order to accomplish it, the relations between the context of production and meaning making of popular scientific text are considered in the reading process.

Keywords: popular science; discourse analysis; Fleck; science teaching.

\footnotetext{
- Bolsista CAPES.
} 


\section{Introdução}

A possibilidade da utilização de textos de divulgação científica (DC) no contexto do ensino formal vem sendo discutida recentemente por pesquisas na área de ensino de ciências. Estas possivelmente têm como fatores propulsores as constantes críticas ao livro didático - tecidas tanto pelos inúmeros estudos acadêmicos quanto por políticas públicas como o Plano Nacional do Livro Didático - e a própria observação (na maioria das vezes não sistematizada) de que os professores de ciências vêm experimentando o uso desses textos como um material alternativo ao livro didático.

Estudos recentes têm explorado diferentes aspectos que dizem respeito ao emprego de textos de DC no ambiente escolar, seja por meio da descrição de suas características lingüísticas (GOMES, 1995; GOUVÊA, 2000; MASSARANI e MOREIRA, 2001; NASCIMENTO, 2004; SILVA, 2003; ZAMBONI, 2001), seja pela investigação de tópicos relacionados à seleção de reportagens de revistas e jornais por parte de professores de ciências (ROCHA, 2003; TERRAZAN, 1998). Além disso, algumas pesquisas destacam o emprego de textos de DC como alternativa ao uso do livro didático na construção de conceitos científicos (ALMEIDA, 1998; ALVETTI, 1999; CRUZ et al., 2000; SALÉM e KAWAMURA, 1996) ou discutem as transposições e mediações que envolvem o emprego de tais textos em aulas de ciências (AIRES et al., 2003; CHAVEZ e MACHADO, 2005; CHELINI e MARANDINO, 2004; MARTINS et al., 2004; TERRAZAN e GABANA, 2003).

Podemos observar, com base nos referidos estudos, que grande parte dos trabalhos que têm a DC como objeto concentram-se na investigação de aspectos relacionados à utilização de textos de revistas e jornais nas aulas de ciências. Com isso, poucas reflexões teóricas têm sido feitas acerca do contexto de produção da DC e a adaptação de seus textos em aulas de ciências.

Neste trabalho, tenho como objetivo tecer reflexões teóricas sobre a dinâmica de produção da DC por uma comunidade que compartilha determinados pensamentos. Além disso, considero sua posterior inserção no ambiente escolar considerando as possíveis dificuldades geradas na aprendizagem de conceitos científicos durante a utilização do texto de divulgação. Para tanto, utilizo como referenciais teóricos categorias epistemológicas desenvolvidas por Fleck e Bachelard tendo ainda como pano de fundo a Análise do Discurso de escola francesa de modo a explorar características específicas do gênero de discurso divulgação científica e a multiplicidade de sentidos produzidos durante a interação do aluno com o texto de DC na sala de aula.

\section{Relações entre categorias da epistemologia de Fleck e a Divulgação Científica}

A teoria do conhecimento de Ludwik Fleck tem como principais categorias o estilo de pensamento e o coletivo de pensamento. $O$ estilo de pensamento é definido como sendo 
"um perceber dirigido com a correspondente elaboração intelectual e objetiva do percebido" (FLECK, 1986, p.145). O estilo caracteriza-se pelos problemas que interessam ao coletivo, pelos juízos que o pensamento coletivo considera evidentes e pelos métodos que empregam como meio de conhecimento. Além disso, ele proporciona uma coerção sobre os indivíduos determinando o que não pode ser pensado de outra forma.

Por conseqüência, o coletivo de pensamento existe sempre que duas ou mais pessoas compartilham o mesmo estilo de pensamento. $O$ coletivo consiste numa comunidade que não deve ser confundida com um grupo fixo ou uma classe social uma vez que um mesmo indivíduo pode participar de mais de um coletivo de pensamento (FLECK, 1986).

Alguns estudos têm utilizado as categorias acima mencionadas de modo a explorar a dinâmica da circulação de idéias que acontece dentro de um mesmo coletivo (circulação intracoletiva) e entre coletivos distintos (circulação intercoletiva de idéias) em diferentes contextos. Recentemente, um número da revista Studies in History and Philosophy of Biological and Biomedical Sciences (2004) reuniu textos que apresentam pesquisas que utilizam o referencial fleckiano para a compreensão de fatos científicos relacionados a medicina (como por exemplo o estudo histórico da diabetes e da tuberculose).

No Brasil, a epistemologia de Fleck também tem sido utilizada como referencial para análises na área da medicina e saúde - como nos estudos de Da Ros (1999) e de Cutolo (1999) - e no ensino de ciências. Em Delizoicov (2004), por exemplo, categorias fleckianas são utilizadas para caracterizar a área de ensino de ciências como um campo que se organiza em coletivos de pensamento que investigam problemas relativos à disseminação sistematizada de conhecimentos científicos. O autor discute como estes coletivos estabelecem comunicações (intra e intercoletivos) em variados graus permitindo assim a constituição da pesquisa em ensino de ciências no Brasil como um campo social de produção de conhecimento.

Alguns outros estudos têm utilizado categorias epistemológicas de Fleck para proporem a inserção de aspectos da história da ciência no ensino de biologia (genética). Leite e cols. (2001), por exemplo, compreendem que a participação de Mendel em diversos coletivos de pensamento teria sido determinante para o desenvolvimento de suas leis de herança dos caracteres. Já no trabalho de Scheid e cols. (2003) é discutida a evolução do conhecimento científico que culminou com a proposição do modelo de dupla hélice para a molécula de DNA e sua aceitação do modelo pela comunidade científica. Ambos os artigos utilizam a epistemologia de Fleck para entender a história da biologia e ressaltam a importância de um ensino de ciências que seja contextualizado historicamente permitindo ao aluno compreender a própria dinâmica da ciência e da produção do conhecimento científico. 
Também numa abordagem histórica-epistemológica, Delizoicov, N. (2002) discute o papel da história da ciência na formação de professores a partir de um estudo das explicações sobre o movimento do sangue no corpo humano. Aqui, as categorias de Fleck são utilizadas para examinar os modelos explicativos sobre circulação sangüínea que se sucederam ao longo do tempo. Segundo a autora, tal abordagem histórica ajudaria professores a compreender a identificação e formulação de problemas que são colocados pelo coletivo dos pesquisadores de uma época, vislumbrando assim que a produção do conhecimento científico não se dá de modo individual nem linear.

Neste artigo, em específico, busco articular as referidas categorias fleckianas com o contexto de produção da DC. A DC é definida por Bueno (1985) ${ }^{1}$ como a popularização de conhecimentos científicos para um público de não especialistas. De acordo com este autor, a DC é produzida por um grupo de especialistas num determinado tópico que tem como propósito apresentar para um público leigo atualidades concernentes a sua área específica de atuação e/ou conhecimento. Apesar da comunicação para esse tipo de público também ser realizada por cientistas, percebe-se que grande parte dos textos de divulgação tem sido elaborada por jornalistas havendo colaboração ou não de especialistas (GOUVÊA, 2000).

Se pensarmos o contexto de produção da DC utilizando para isso as categorias epistemológicas de Fleck, veremos que é possível caracterizar o grupo de produtores de DC (sendo ele formado pela interseção dos coletivos de cientistas e jornalistas; ver Figura 1) como constituindo um círculo esotérico (FLECK, 1986) uma vez que seus integrantes compartilham um estilo de pensamento e, concomitantemente, compõem um coletivo de pensamento (ALVETTI e CUTOLO, 2005).

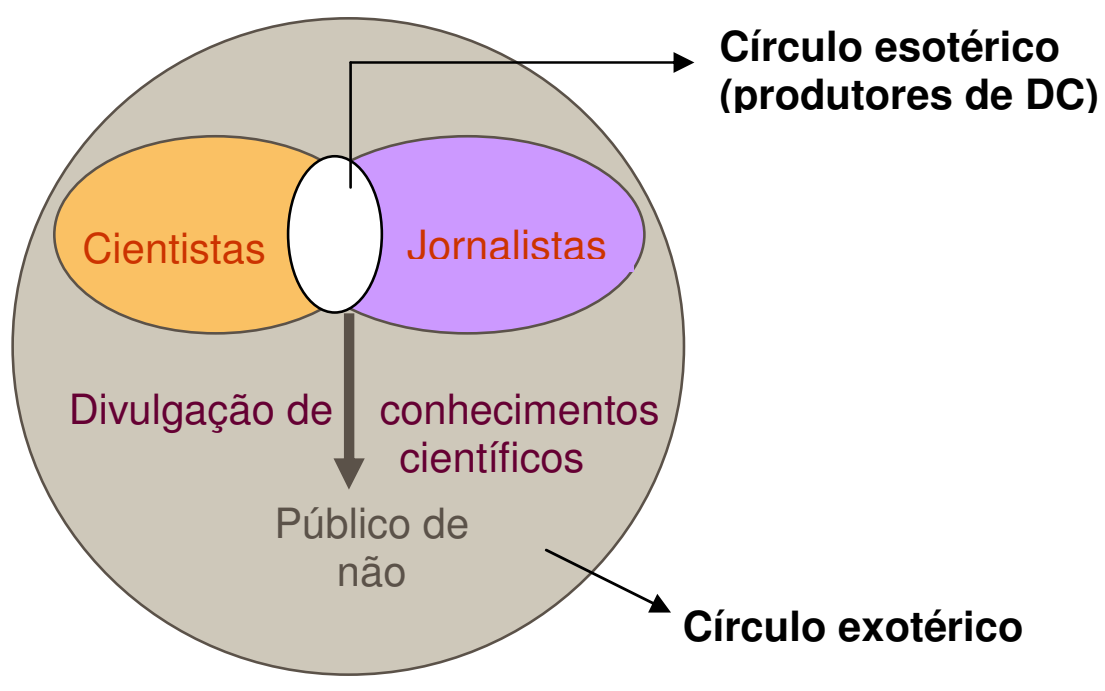

\footnotetext{
1 Este autor promove ainda a distinção entre disseminação e divulgação científica. Ambas constituem-se modalidades do que ele chama difusão científica a qual consiste em "todo e qualquer processo ou recurso utilizado para veiculação de informações científicas e tecnológicas" (BUENO, 1985, p.1421). Ao contrário da divulgação, a disseminação diz respeito à difusão de conhecimentos que os cientistas fazem entre os pares.
} 
Figura 1: Relação entre os círculos esotérico e exotérico no contexto da divulgação científica.

Ao redor desse círculo esotérico existe um grande círculo exotérico (FLECK, 1986) composto pelo público de não especialistas. No caso específico da DC, o conhecimento científico é apresentado aos leigos por meio da mediação feita por aqueles que são iniciados numa área específica. Segundo Fleck (1986),

o círculo exotérico não tem relação direta com aquela criação do pensamento, senão somente uma indireta através da mediação do círculo esotérico. A relação da maioria dos membros do coletivo de pensamento com as criações ou produtos do estilo de pensamento se baseia na confiança depositada nos iniciados (p.152).

A circulação intercoletiva de idéias (ou seja, a troca de informações existente entre os dois círculos) é compreendida por Fleck como algo dinâmico, que ocorre numa via de mão dupla². Assim, "do saber especializado (esotérico) surge o popular (exotérico)". Aquele, forma a opinião pública específica e a concepção de mundo e, assim, o círculo exotérico repercute no especialista (FLECK, 1986, p.161).

Além disso, existe a possibilidade de que dentro do círculo esotérico ocorra a circulação de idéias, ao que Fleck chama de circulação intracoletiva de idéias ${ }^{3}$. Este epistemólogo promove, então, uma caracterização dos suportes materiais responsáveis pela veiculação de idéias científicas intra e intercoletivas a partir da distinção entre a ciência dos especialistas (saber especializado do círculo esotérico) e a ciência popular (saber popular do círculo exotérico) (FLECK, 1986).

A comunicação intracoletiva dar-se-ia então por meio das revistas (para os pares) e dos manuais (para os cientistas em formação) e a intercoletiva através de livros-texto (destinados à iniciação à ciência na escola) e de livros de divulgação ou populares (destinados a um público mais amplo). Estes últimos (incluindo também outras formas de apresentações populares, como os jornais e revistas não especializadas) consistem no foco deste artigo. De acordo com Fleck, uma apresentação popular de conhecimentos científicos caracteriza-se pela omissão dos detalhes, principalmente dos aspectos ainda em discussão entre os especialistas, de modo que se atinja uma simplificação artificial. Em suas palavras:

\footnotetext{
${ }^{2}$ A circulação intercoletiva de idéias pode ocorrer nos dois sentidos, porém, neste artigo destaco apenas o movimento existente desde o grupo de produtores da DC para o público não especialista.

${ }^{3}$ No caso do coletivo de pensamento exclusivo dos cientistas, a circulação intracoletiva fica caracterizada pela disseminação dos conhecimentos científicos intrapares (BUENO, 1985).
} 
$A$ isto [características de omissão e simplificação] se une uma exposição artisticamente atrativa, viva e gráfica e, por último, uma valorização convincente consistente com o simples aceitar ou rejeitar certos pontos de vista (FLECK, 1986, p.161).

Se nos aproximamos mais do grande círculo dos que têm uma "formação geral", então o saber se faz ainda mais gráfico e mais simples; ao mesmo tempo desaparecem as provas coercionadoras do pensamento e se faz ainda mais convincente (idem, p.163).

Estas características atribuídas por Fleck aos livros de divulgação são corroboradas pelo estudo empírico realizado por ZAMBONI (2001) com textos de revistas de DC. Neste trabalho, a autora destaca, entre outros pontos, os recursos utilizados pelos divulgadores para atrair a atenção do leitor como, por exemplo, a inserção de imagens (fotos, desenhos, gráficos e esquemas) e a presença de títulos de reportagens - ambos apresentados em cores que se destacam do corpo do texto principal - que constituem apelos iniciais à leitura. Além disso, a autora detecta a presença de procedimentos explicativos que promovem a simplificação de determinados fenômenos científicos.

A circulação intercoletiva de idéias apenas é possível quando se tratam de dois círculos que apresentam certo nível de convergência. De acordo com Fleck (1986), "quanto maior é a diferença de dois estilos de pensamento menor é a circulação intercoletiva de idéias" (p.155). Assim, fatos e conceitos de um coletivo de pensamento poderão ser considerados por componentes de um outro coletivo desde que: primeiro, tratem-se de coletivos pouco divergentes; e, segundo, tais fatos e conceitos sejam traduzidos em outra linguagem de pensamento.

Nesse sentido, Fleck argumenta que a circulação intercoletiva de idéias não pode acontecer sem uma transformação do conhecimento.

Toda circulação intercoletiva de idéias tem por conseqüência um deslocamento ou transformação dos valores dos pensamentos (FLECK, 1986, p. 156).

A comunicação não ocorre nunca sem transformação e sem que se produza uma remodelização de acordo com o estilo, que intracoletivamente se traduz em um reforço e intercoletivamente em uma mudança fundamental do pensamento comunicado (idem, p. 158).

Fleck destaca a palavra como sendo o principal objeto de circulação intercoletiva. Ao sair de um círculo esotérico para um exotérico, a palavra acaba por adquirir novos significados, na medida em que o público de não especialistas procura dar sentido àquele 
termo específico da linguagem científica de acordo com o nível de conhecimento que ele detém.

A palavra como tal constitui um objeto especial de circulação intercoletiva. Todas as palavras têm aderido um tom estilístico mais ou menos marcado. Este tom muda quando circulam intercoletivamente, o que produz uma certa variação de seu significado (FLECK, 1986, p. 156).

Com base na discussão acima, podemos pensar que durante a produção dos textos de DC seus autores realizam adaptações de conhecimentos científicos, recorrendo por vezes à inserção de estruturas lingüísticas específicas (como, por exemplo, o uso de figuras de linguagem como metáforas e analogias) ou à eliminação de terminologias próprias do discurso científico (NASCIMENTO e MARTINS, 2003). Com isso, buscam apresentar novidades científicas e tecnológicas utilizando uma linguagem mais próxima do cotidiano dos leitores não especialistas, de modo que os principais conceitos e fenômenos tornem-se compreensíveis para o círculo exotérico. Observamos, então, que a partir do esforço dos produtores de DC em adaptar o conhecimento científico para um público leigo, são promovidas transformações no conhecimento científico as quais podem vir a se constituir entraves para a aprendizagem de conceitos na educação formal.

\section{O discurso da Divulgação Científica: as condições de produção e de circulação intercoletivos}

Na Análise de Discurso (AD) de linha francesa, o discurso é compreendido como o lugar onde as práticas sociais são materializadas na/pela linguagem (ORLANDI, 1996a). Podemos considerar a divulgação científica como uma prática social que se materializa na forma de textos ${ }^{4}$ verbais (escritos ou orais) e imagéticos.

Por ser um tipo de discurso que comporta um grupo de textos que estão submetidos a coerções comuns que são determinantes de sua organização e conteúdo (MAINGUENEAU, 1989), a DC pode ser ainda compreendida como um gênero de discurso específico. Esta consideração baseia-se no fato de que a DC consiste no resultado de uma atividade discursiva que se desenvolve em condições de produção ${ }^{5}$ inteiramente diferentes daquelas em que o conhecimento científico é produzido pelos cientistas. As condições de produção do discurso da DC estão relacionadas com o enunciador/autor (componente do círculo esotérico), com o destinatário (público não especializado e, portanto, integrantes do

\footnotetext{
${ }^{4}$ O texto, para a AD, consiste na forma empírica do uso da linguagem (PINTO, 1999), na unidade de análise do discurso (ORLANDI, 1993).

${ }^{5}$ Segundo o referencial da AD, as condições de produção envolvem o contexto histórico-social de formulação do texto, os interlocutores (autor e leitor), os lugares onde eles se situam, as imagens que eles fazem de si e dos outros e o objeto da fala (ORLANDI, 1999).
} 
círculo exotérico), com o tratamento a ser dado ao assunto e com a construção composicional. Como resultado dessas condições de produção temos a superposição de traços de cientificidade, laicidade e didaticidade, que se deixam mostrar em graus variados na superfície do texto de divulgação (ZAMBONI, 2001).

O discurso da DC pode ser caracterizado com base nos três elementos essenciais de qualquer gênero do discurso: o tema, o estilo e a composição (BAKHTIN, 1992). Com relação ao tema, o discurso da divulgação veicula conteúdos próprios à temática científica englobando, de forma mais ampla, temas sobre "ciência e tecnologia". No que diz respeito ao estilo, e por ser dirigido a um destinatário leigo,

o discurso da divulgação científica deve dispensar a linguagem esotérica exigida pelo discurso científico preparado por e para especialistas e abrir-se para o emprego de analogias, aproximações, comparações. Simplificações - recursos que contribuem para corporificar um estilo que vai se constituir como marca da atividade de vulgarização discursiva (ZAMBONI, 2001, p.89).

Finalmente, no aspecto composicional, as formas de estruturação do discurso da divulgação científica põem em funcionamento procedimentos discursivos nos quais se incluem, entre outros, a recuperação de conhecimentos tácitos, a segmentação da informação, fórmulas de envolvimento, a presença de procedimentos explicativos, busca de credibilidade e a interlocução direta com o leitor.

Com base nas características da DC comentadas acima, podemos aproximar o conceito da $A D$ de gênero do discurso à categoria epistemológica fleckiana coletivo de pensamento. De acordo com Fleck, o coletivo de pensamento detentor de certo grau de estabilidade corresponde a um estilo que possui conteúdos, forma e tema exclusivos, além de mobilizar uma linguagem específica que o isola dos demais coletivos.

As comunidades de pensamento estáveis (ou comparativamente estáveis) cultivam, como outras comunidades organizadas, uma certa exclusividade formal e temática. Disposições legais e hábitos arraigados, às vezes uma linguagem especial - ou ao menos termos especiais - isolam formalmente, ainda que não de forma absolutamente obrigatória, a comunidade de pensamento (FLECK, 1986, p. 150).

Outros aspectos fundamentais para a produção dos textos de DC são as formações imaginárias e ideológicas que os autores fazem tanto de sua audiência quanto do seu objeto de escrita. As formações imaginárias irão designar o lugar que o enunciador e o coenunciador da comunicação atribuem a si mesmo e ao outro, a imagem que fazem deste lugar que ocupam e a imagem do referente. Portanto, irão influenciar na produção do texto: 
a imagem que quem diz tem de si mesmo; a imagem de quem escuta ou lê; e a imagem do que diz. É importante ressaltar que estas imagens não são resultado de elaborações internas individuais neutras, mas "assentam-se no modo como as relações sociais se inscrevem na história e são regidas, em uma sociedade como a nossa, por relações de poder" (ORLANDI, 1999). Já a formação ideológica constitui "um conjunto complexo de atitudes e de representações que não são nem 'individuais' nem 'universais' mas se relacionam mais ou menos diretamente a posições de classe em conflito umas em relação às outras" (HAROCHE et al. apud CARDOSO, 1999).

Retomando o contexto da DC, notamos que os protagonistas do discurso (neste caso, os produtores da DC) estão revestidos de representações imaginárias que os situam em determinado lugar na estrutura social e que influenciam na produção do texto (ORLANDI, 1999). Devemos ressaltar ainda que as formações imaginárias e ideológicas se fazem fundamentais no momento de significação do texto, ou seja, durante o processo de leitura em que há a interação por parte do leitor com as idéias do autor e, conseqüentemente, quando ocorre a construção de sentidos.

As diferentes possibilidades de significação a partir da leitura de textos de DC na sala de aula são discutidas na seção seguinte. Além disso, retomo a questão das implicações que as adaptações do conhecimento científico realizadas no processo de elaboração de textos de DC têm na aprendizagem de conceitos por parte dos alunos durante o uso dos mesmos em aulas de ciências.

\section{Divulgação Científica na escola: obstáculo à aprendizagem de conceitos científicos?}

Poucos estudos que exploram a questão do uso de textos de DC em aulas de ciências têm se dedicado a aprofundar as dificuldades que tais tipos de textos trariam para a aprendizagem de conceitos científicos. Mesmo sem realizar um estudo empírico, podemos refletir acerca das diferentes possibilidades de significação que são geradas a partir do contato do aluno com um texto que, a princípio, não foi produzido com o intuito de ser utilizado no ensino formal.

Podemos reconhecer que os possíveis problemas de aprendizagem decorrentes do emprego de textos DC na escola podem ter duas origens as quais se encontram relacionadas às mediações que ocorrem: a) na produção do texto de DC, mais especificamente, no processo de adaptação e transformação do conhecimento científico para uma linguagem menos esotérica destinada ao público de não especialistas; b) na sua inserção na sala de aula, quando o aluno entra em contato com esse texto. Estes dois níveis de mediação são fundamentais durante o processo de aprendizagem podendo vir a 
constituir obstáculos pedagógicos ${ }^{6}$ (BACHELARD, 1996), ou seja, "entraves que impedem o aluno de compreender o conhecimento científico" (LOPES, 1993, p.316) (ver Figura 2).

A primeira mediação, localizada durante a elaboração do texto, é caracterizada pela remodelização do conhecimento científico. Este processo é fundamental para a aprendizagem, pois de acordo a linguagem utilizada no texto de DC os conceitos científicos poderão ser confundidos, complicados ou até mesmo veiculados de forma errada. Por exemplo, a simplificação da linguagem por meio da utilização de metáforas e analogias pode se constituir num obstáculo verbal ${ }^{7}$ (BACHELARD, 1996).

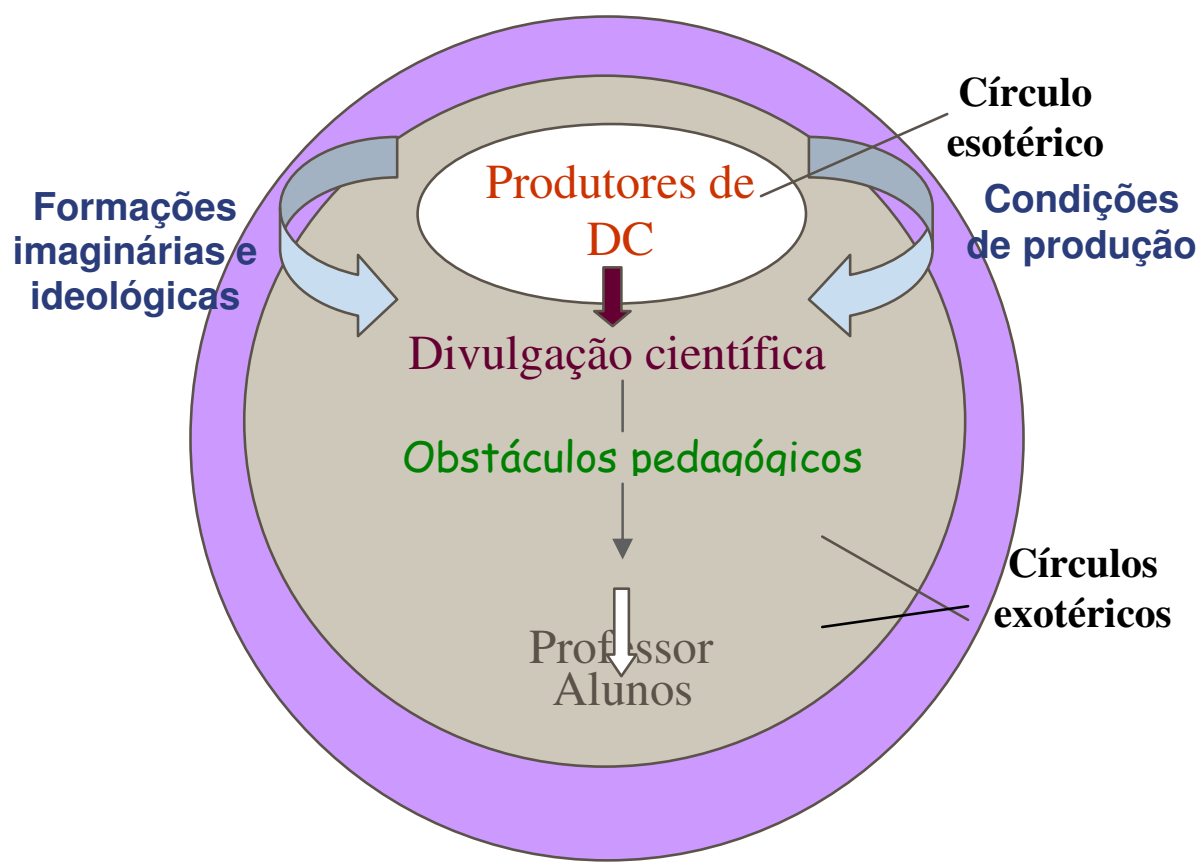

Figura 2: Relações entre o círculo esotérico produtor da divulgação científica e os círculos exotéricos a ele relacionados no âmbito do ensino formal.

A segunda mediação, ocorrida já no âmbito do ensino formal, acontece no ato da leitura. Durante a interação entre leitor e texto, os diferentes sentidos se estabelecem de modo que a compreensão dos conceitos e fenômenos científicos pode estar mais próxima

\footnotetext{
${ }^{6}$ Bachelard (1996) constrói sua teoria do conhecimento científico com base no conceito de obstáculos epistemológicos os quais, segundo ele, são causas de estagnação, regressão e inércia que impedem a formação do espírito científico. Além de explorar a noção de obstáculo epistemológico no desenvolvimento histórico do pensamento científico, Bachelard reflete sobre a prática pedagógica. É em termos de obstáculos pedagógicos que ele comenta as dificuldades que os professores têm em compreender como se dá a aprendizagem de conceitos científicos, isto é, pela impossibilidade de se reconhecer os conhecimentos empíricos já constituídos de seus alunos.

${ }^{7}$ Bachelard (1996) classifica os obstáculos epistemológicos em diferentes tipos, entre eles, o obstáculo verbal que é definido como "a falsa explicação obtida com a ajuda de uma palavra explicativa, nessa estranha inversão que pretende desenvolver o pensamento ao analisar um conceito, em vez de inserir um conceito particular numa síntese racional" (p.27). Ao comentar esse obstáculo, o epistemólogo destaca o perigo do uso de metáforas para a formação do espírito científico, uma vez que nem sempre elas apresentam imagens passageiras; estas "levam a um pensamento autônomo; tendem a completar-se, a concluir-se no reino da imagem" (idem, p.101).
} 
ou mais distante do significado aceito e compartilhado por aqueles que os produzem ${ }^{8}$. É nesse momento em que a simplificação da linguagem científica - freqüentemente traduzida por meio do uso de figuras de linguagem - pode vir a produzir diferentes sentidos e se consolidar ou não como um obstáculo à aprendizagem do conceito correto cientificamente.

Nos dois casos em que ocorrem as mediações existe a possibilidade de que ocorram deslocamentos de sentido, ou seja, que diferentes compreensões sejam estabelecidas por diferentes alunos a partir do contato com um mesmo texto. Para a $A D$, os deslocamentos de sentidos são possíveis devido ao fato do sentido não se encontrar inscrito no texto existindo, portanto, a possibilidade de diferentes compreensões por distintos sujeitos (ORLANDI, 1996b). Isso acontece pelo fato de cada leitor possuir diferentes histórias de leitura e, desta forma, construir diferentes intertextos (isto é, tecer relações com textos lidos anteriormente) de modo que o sentido pode ser alargado ou restringido (ORLANDI, 1984).

Com relação a esta possibilidade de alteração de sentidos, Fleck (1986) comenta:

[...] a variação de atitude com a circulação intercoletiva de idéias causa uma variação desses valores em uma escala completa de possibilidades: desde pequenas mudanças de tom, passando pela mudança quase completa de sentido, até a destruição total do mesmo [...] (p.156).

Uma forma de reduzir os possíveis deslocamentos de sentido durante a leitura geralmente adotada pelos professores no momento em que os textos são utilizados em sala de aula - consiste em adaptações que são feitas de acordo com os seus objetivos didáticopedagógicos. Nesta etapa, os professores selecionam, complementam e destacam determinadas informações que Ihes interessam, além de estabelecerem relações com conceitos e fenômenos anteriormente estudados (MARTINS et al., 2004). Com isso, os professores retomam uma leitura que é considerada ideal e que tem como modelo a leitura feita por um especialista (ORLANDI, 1984) ${ }^{9}$.

\section{Buscando um diálogo...}

O esquema representado na Figura 3 busca representar e articular as reflexões tecidas até aqui. O círculo esotérico constituído pelo coletivo de pensamento de cientistas e jornalistas é responsável pela produção da DC. Tal produção é determinada por condições relacionadas às formações imaginárias e ideológicas de seus autores e também pelas

\footnotetext{
${ }^{8}$ De acordo com Orlandi (1984), "há leituras previstas para um texto" (p.7). Esta previsibilidade tem como elementos determinantes os sentidos históricos (relacionados aos funcionamentos do texto num tempo histórico) e a intertextualidade (conjunto de relações entre os textos que mostram como o texto deve ser lido).

${ }^{9}$ Segundo Orlandi (1984), há especialistas que legitimam o processo histórico da leitura e que podem ser considerados críticos nos diversos domínios científicos. Assim, "ao mesmo tempo em que avaliam a importância de um texto, os críticos fixam-lhe um sentido que é considerado o desejado (o prestigiado) para a leitura" (p.8). É nesse circuito da leitura de prestígio em que atua o professor de ciências.
} 
características deste gênero do discurso, as quais influenciam na forma, estrutura e composição do texto.

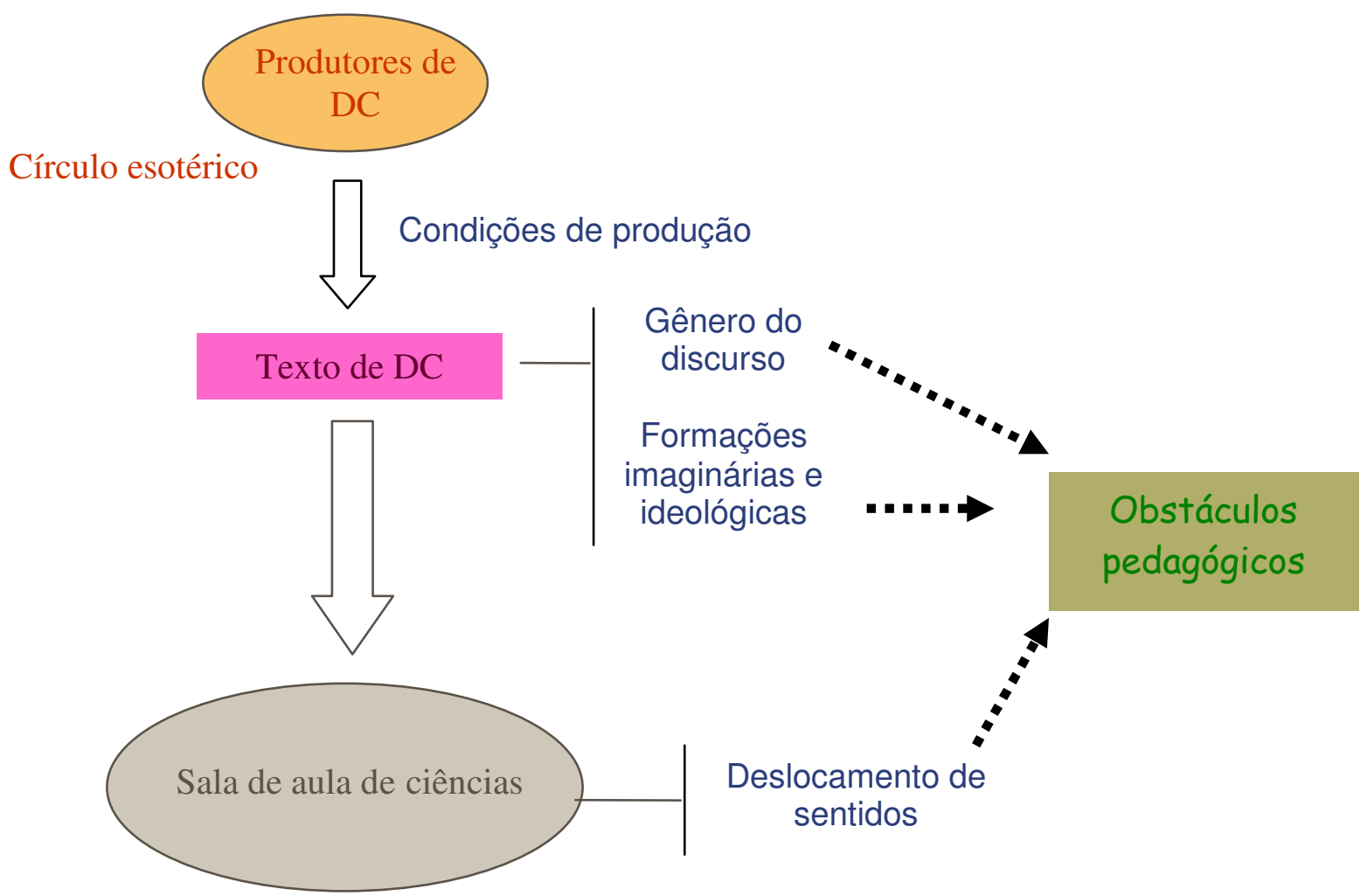

\section{Círculo exotérico}

Figura 3: Resumo esquemático das possíveis articulações entre categorias epistemológicas de Fleck e Bachelard e a Análise do Discurso no contexto da divulgação científica.

O texto de DC é elaborado para um público de não especialistas e por isso envolve um esforço de adaptação da linguagem que promove uma transformação do conhecimento científico. Este texto não foi necessariamente escrito com a pretensão de vir a circular num ambiente de ensino formal e, por isso, caso venha a ser inserido em aulas de ciências poderá contribuir para a constituição de obstáculos pedagógicos.

É no âmbito da escola que dois círculos exotéricos distintos têm contato, de forma sistemática, com a DC. Inicialmente, os professores de ciências (que constituem um círculo exotérico de leigos formados) apropriam-se das informações veiculadas pelo texto de $\mathrm{DC}^{10}$ e, em seguida, promovem sua inserção na aula de ciências. Geralmente, esta etapa é

\footnotetext{
${ }^{10}$ Vale ressaltar que esta apropriação do discurso da DC por meio de textos de revistas, jornais etc. pelo professor não necessariamente se dá na escola, podendo ocorrer em diversos espaços fora dela.
} 
precedida por um processo de adaptação/mediação feito pelo professor que pode acontecer antes e durante a utilização do texto em sala de aula.

Devido a esta circulação intercoletiva de idéias, os diferentes conceitos científicos adquirem diferentes sentidos que podem estar mais próximos ou mais distantes daquele considerado como o ideal pelos especialistas. Nesse contexto, a aprendizagem formal de conceitos científicos pode ser dificultada devido às mediações realizadas ao longo dos processos de produção do texto de divulgação e da leitura.

\section{Considerações finais}

O presente trabalho pretendeu realizar um aprofundamento teórico sobre a divulgação científica de modo a tecer reflexões que integrassem a epistemologia de Fleck e categorias da Análise do Discurso no âmbito do ensino de ciências. Aqui foram apontados alguns aspectos concernentes à produção de textos de divulgação e sua inserção na sala de aula que se encontram relacionados à aprendizagem formal de conceitos científicos.

Nesse sentido, pudemos perceber que a utilização das categorias epistemológicas de Fleck, em articulação com alguns conceitos da análise do discurso francesa, nos permitiu ter uma melhor compreensão da divulgação científica no que diz respeito a dois pontos centrais. O primeiro refere-se à possibilidade de realizarmos uma reflexão de cunho explicitamente epistemológico acerca da divulgação científica, ponto este fundamental para o entendimento da dinâmica de produção e de circulação de informações envolvida com a comunicação científica. O segundo está mais relacionado à aprendizagem de conceitos científicos por meio da utilização de textos de divulgação científica que tem como cenário um espaço formal de ensino. Aqui me refiro a uma análise que, a partir das categorias de Fleck e da análise do discurso, nos subsidia na compreensão das transformações que podem ocorrer no estilo de pensamento dos alunos ao interagirem com textos de divulgação científica.

Apesar deste trabalho não ter tido como objetivo a observação do uso de textos de DC numa situação real de interação entre alunos e texto, algumas elucubrações acerca das possíveis significações e obstáculos à aprendizagem decorrentes desse contato foram tecidas. Por este motivo, fazem-se necessários estudos empíricos que venham a explorar a questão da construção de sentidos de modo que as reflexões feitas neste artigo possam vir a serem corroboradas ou reformuladas. 


\section{Referências Bibliográficas}

AIRES, Joanez et al. Divulgação científica na sala de aula: um estudo sobre a contribuição da revista Ciência Hoje das Crianças. In: ENCONTRO NACIONAL DE PESQUISA EM EDUCAÇÃO EM CIÊNCIAS, 4., 2003, Bauru, SP. Atas... Porto Alegre: ABRAPEC, 2003. 1 CD.

ALMEIDA, Maria José P. M. O texto escrito na educação em física: enfoque na divulgação científica. In: ALMEIDA, Maria José P. M. e SILVA, Henrique César (Orgs.) Linguagens, leituras e ensino da ciência. Campinas, SP: Mercado de Letras: Associação de Leitura do Brasil, 1998. 208 p.

ALVETTI, Marco Antônio S. Ensino de física moderna e contemporânea e a revista Ciência Hoje. 1999. 169f. Dissertação (Mestrado em Educação) - Centro de Ciências da Educação, Universidade Federal de Santa Catarina, Florianópolis.

ALVETTI, Marco Antônio S. e CUTOLO, Luiz Roberto A. Uma visão epistemológica da circulação de idéias presentes na comunicação científica. In: SIMPÓSIO NACIONAL DE ENSINO DE FÍSICA, 16., 2005, Rio de Janeiro. Programa e Resumos... Rio de Janeiro: SBF: CEFET/RJ: UERJ, 2005.

BACHELARD, Gaston. A formação do espírito científico. Rio de Janeiro: Contraponto, 1996. $316 \mathrm{p}$.

BAKHTIN, Mikhail. Estética da criação verbal. São Paulo: Martins Fontes (Coleção Ensino Superior), 1992. 510 p.

BUENO, Wilson da C. Jornalismo científico: conceitos e funções. Ciência e Cultura, Campinas, 37 (9), p. 1420-1427, 1985.

CARDOSO, Sílvia Helena B. Discurso e ensino. Belo Horizonte: Autêntica, 1999. 168 p.

CHAVEZ, Taniamara V. e MACHADO, Rodrigo Batista. Uma proposta para o ensino de física com textos de divulgação científica. In: SIMPÓSIO NACIONAL DE ENSINO DE FíSICA, 16., 2005, Rio de Janeiro. Programa e Resumos... Rio de Janeiro: SBF: CEFET/RJ: UERJ, 2005. 
CHELINI, Maria-Júlia Estefânia e MARANDINO, Martha. Recursos lingüísticos e extralingüísticos em textos de divulgação: um estudo piloto sobre o tema moluscos. In: ENCONTRO PERSPECTIVAS DO ENSINO DE BIOLOGIA, 9., 2004, São Paulo. Caderno de Programa e Resumos... Campinas, SP: Graf. FE, 2004.

CRUZ, Frederico F. de S.; FERRARI, Nadir e RIBEIRO, Maria Cecília M. O uso da divulgação científica como instrumento didático num tema interdisciplinar. In: ENCONTRO DE PESQUISA EM ENSINO DE FÍSICA, 7., 2000, Florianópolis. Resumos... São Paulo: SBF, 2000. 1 CD.

CUTOLO, Luiz Roberto A. e DELIZOICOV, Demétrio. O currículo do curso de graduação em medicina da UFSC: análise a partir das categorias fleckianas. In: ENCONTRO NACIONAL DE PESQUISA EM EDUCAÇÃO EM CIÊNCIAS, 2., 1999, Valinhos. Atas... Porto Alegre: ABRAPEC, 1999. 1 CD.

DA ROS, Marco Aurélio e DELIZOICOV, Demétrio. Estilos de pensamento em saúde pública. In: ENCONTRO NACIONAL DE PESQUISA EM EDUCAÇÃO EM CIÊNCIAS, 2., 1999, Valinhos. Atas... Porto Alegre: ABRAPEC, 1999. 1 CD.

DELIZOICOV, Demétrio. Pesquisa em ensino de ciências como ciências humanas aplicadas. Caderno Brasileiro de Ensino de Física, Florianópolis, v. 21, n. 2, ago. 2004.

DELIZOICOV, Nadir C. O movimento do sangue no corpo humano: história e ensino. 2002. 253 f. Tese (Doutorado em Educação) - Centro de Ciências da Educação, Universidade Federal de Santa Catarina, Florianópolis.

FLECK, Ludwik. La génesis y el desarollo de un hecho científico. Madrid: Alianza Editorial, 1986. 200 p.

GOMES, Isaltina M. A. M. Dos laboratórios aos jornais: um estudo sobre jornalismo científico. 1995. 232 f. Dissertação (Mestrado em Lingüística) - Centro de Artes e Comunicação, Universidade Federal de Pernambuco, Recife.

GOUVÊA de Sousa, Guaracira. A Divulgação Científica para Crianças: o caso da Ciência Hoje das Crianças. 2000. Tese (Doutorado em...) - Departamento de Bioquímica Médica, Universidade Federal do Rio de Janeiro, Rio de Janeiro. 
LEITE, Raquel C. M.; FERRARI, Nadir e DELIZOICOV, Demétrio. A história das leis de Mendel na perspectiva fleckiana. Revista Brasileira de Pesquisa em Educação em Ciências, Porto Alegre, 1(2), p.97-108, 2001.

LOPES, Alice R. C. Livros didáticos: obstáculos verbais e substancialistas ao aprendizado da ciência química. Revista Brasileira de Estudos Pedagógicos, Brasília, v.74, n.177, p.309-334, 1993.

MAINGUENEAU, Dominique. Novas tendências em análise do discurso. Campinas: Pontes: Ed. da UNICAMP, 1989. 198 p.

MARTINS, Isabel; NASCIMENTO, Tatiana G. e ABREU, Teo B. Clonagem na sala de aula: um exemplo do uso didático de um texto de divulgação científica. Investigações em Ensino de Ciências, Porto Alegre, vol.9, n.1, mar. 2004. Disponível em < http://www.if.ufrgs.br/public/ensino/>

MASSARANI, Luiza e MOREIRA, Ildeu C. A retórica e a ciência: dos artigos originais à divulgação científica. Ciência \& Ambiente, Santa Maria, 23, p. 31-47, 2001.

NASCIMENTO, Tatiana G. Adaptações de um texto de divulgação científica sobre clonagem para um livro didático de ciências. In: ENCONTRO PERSPECTIVAS DO ENSINO DE BIOLOGIA, 9., 2004, São Paulo. Caderno de Programa e Resumos... Campinas, SP: Graf. FE, 2004.

NASCIMENTO, Tatiana G. e MARTINS, Isabel. Análise do movimento de re-elaboração discursiva em dois textos de divulgação científica. In: Simpósio Nacional de Ensino de Física, 15., 2003, Curitiba. Disponível em <http://www.sbf1.sbfisica.org.br/eventos/snef/xv/> ORLANDI, Eni P. As histórias das leituras. Leitura: teoria \& prática. Porto Alegre: Mercado Aberto, Ano 3, p. 7-9, jul. 1984.

Discurso e leitura. 2. ed. São Paulo: Cortez, 1993. 168 p.

A linguagem e seu funcionamento: as formas do discurso. 4. ed. São Paulo: Pontes, 1996a. 280 p.

Interpretação: autoria, leitura e efeitos do trabalho simbólico. 2. ed. Petrópolis, RJ:

Vozes, 1996b. $150 \mathrm{p}$. 
Análise de discurso: princípio e procedimentos. Campinas: Pontes, 1999. 100 p.

PINTO, Milton José. Comunicação e discurso: introdução à análise de discursos. São Paulo: Hacker Editores, 1999. 128 p.

ROCHA, Marcelo B. O potencial didático dos textos de divulgação científica segundo professores de ciências. 2003. Dissertação (Mestrado em Tecnologia Educacional) Núcleo de Tecnologia Educacional para a Saúde, Universidade Federal do Rio de Janeiro, Rio de Janeiro.

SALÉM, Sônia e KAWAMURA, Maria Regina. O texto de divulgação e o texto didático: conhecimentos diferentes? In: ENCONTRO DE PESQUISADORES EM ENSINO DE FíSICA, 5., 1996. Belo Horizonte. Atas... São Paulo: SBF, 1996.

SCHEID, Neusa Maria J.; DELIZOICOV, Demétrio e FERRARI, Nadir. A proposição do modelo de DNA: um exemplo de como a história da ciência pode contribuir para o ensino de genética. In: ENCONTRO NACIONAL DE PESQUISA EM EDUCAÇÃO EM CIÊNCIAS, 4., 2003, Bauru, SP. Atas... Porto Alegre: ABRAPEC, 2003. 1 CD.

SILVA, Leandro L. As analogias na divulgação científica: o caso da Ciência Hoje das crianças. In: ENCONTRO NACIONAL DE PESQUISA EM EDUCAÇÃO EM CIÊNCIAS, 4., 2003, Bauru, SP. Atas... Porto Alegre: ABRAPEC, 2003. 1 CD.

STUDIES IN HISTORY AND PHILOSOPHY OF BIOLOGICAL AND BIOMEDICAL SCIENCES, vol. 35. Cambridge, UK: Elsevier, 2004.

TERRAZAN, Eduardo Adolfo. O potencial didático dos textos de divulgação científica: um exemplo em física. In: ALMEIDA, Maria José P. M. e SILVA, Henrique César (Orgs.) Linguagens, leituras e ensino da ciência. Campinas, SP: Mercado de Letras: Associação de Leitura do Brasil, 1998. 208 p.

TERRAZAN, Eduardo Adolfo e GABANA, Marciela. Um estudo sobre o uso de atividades didáticas com texto de divulgação científica em aulas de física. In: ENCONTRO NACIONAL DE PESQUISA EM EDUCAÇÃO EM CIÊNCIAS, 4., 2003, Bauru, SP. Atas... Porto Alegre: ABRAPEC, 2003. 1 CD. 
ZAMBONI, Lílian Maria S. Cientistas, jornalistas e a divulgação científica: subjetividade e heterogeneidade no discurso da divulgação científica. Campinas, SP: Autores Associados, 2001. 167 p. 